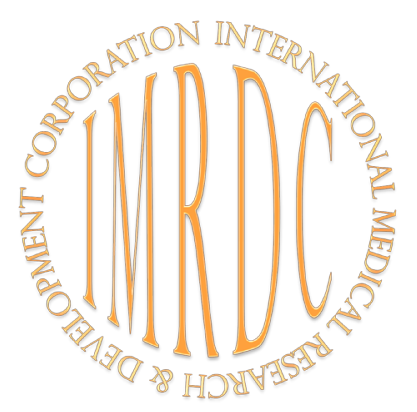

\title{
Short-term HRV Biofeedback: Perspectives in Environmental Physiology and Medicine
}

\author{
Liliya V. Poskotinova, $\mathrm{PhD}, \mathrm{ScD}^{*}$; Denis B. Demin, $\mathrm{PhD}, \mathrm{ScD}$; \\ Elena V. Krivonogova, $\mathrm{PhD}$ \\ Federal Center for Integrated Arctic Research, the Russian Academy of Science \\ Arkhangelsk, the Russian Federation
}

\begin{abstract}
This review demonstrates the effectiveness of short-term HRV biofeedback sessions in an evaluation of human adaptation to uncomfortable environments. A single HRV biofeedback session can be used as a test for the effectiveness of cortical-visceral connections in patients with cardiovascular disease. In addition, this method can be used as short-term assistance in adaptation to social stressful factors. (Int J Biomed. 2017;7(1):24-27.)
\end{abstract}

Key Words: heart rate variability • biofeedback • adaptation $\bullet$ HRV spectrum

\section{Abbreviations}

BP, blood pressure; EEG, electroencephalogram; HR, heart rate; HRV, heart rate variability; HRVB, HRV biofeedback.

The aim of this brief review was to determine the importance of short-term HRVB sessions in environmental physiology and medicine.

HRV analysis retains its relevance as a non-invasive and effective procedure to evaluate adaptation reserves of cardiac activity ${ }_{,}^{[1]}$ to predict biological age.$^{[2]}$ Currently, much attention is paid to relations between functions of the brain and autonomic nervous regulation of the heart rhythm. ${ }^{[3]}$ Neuroimaging methods enabled identification of the brain areas where these relationships are the most important (the amygdala, ventromedial prefrontal cortex of the brain) HRV may be an indicator of how well "vertical integration" of cortico-visceral nervous connections are functioning, providing flexible control of behavior and function of internal organs. ${ }^{[4]}$ During the emotional stress experienced by people with social phobias, a relationship was established between a decrease in the high-frequency component of the HRV spectrum and increased cerebral regional blood flow in certain Brodmann

*Corresponding author: Liliya V. Poskotinova, PhD, ScD. Department of Biorhythmology of Federal Center for Integrated Arctic Research, the RAS, Arkhangelsk, Russia. E-mail: liliya200572@mail.ru areas (in the right caudal nucleus, right anterior cingulate and bilateral medial prefrontal cortex as well as in the dorsolateral prefrontal cortex of the left brain hemisphere).$^{[5]}$ The neurogenic structures responsible for maintaining the high-frequency component of the HRV spectrum (vagal activity) were found in the same areas that are responsible for the different emotions (sadness, happiness, disgust) - the left insular part and caudal nucleus. ${ }^{[6]}$ Arrhythmogenic changes in the bioelectric heart activity, which are considered as predictors of the sudden cardiac death, are correlated with changes in regional blood flow in the right brain. ${ }^{[7]}$ In recent years, HRV analysis has been increasingly used not only for diagnosis, but also as an instrument for correction of an impaired relationship in the "brain-heart" system.

General biological laws of biofeedback have been identified on the basis of classical conditioning by Pavlov ${ }^{[8]}$ and operant conditioning by Skinner. ${ }^{[9]}$ Transmission paths for conditional visual signals are caused by training with modifications of discharges on the conditioned signal during HR control. These "variable" neurons receive information from the unconditioned signal and then modify their activity in accordance with the nature of the conditioned signal. These changes are found in the locus coeruleus of the brain. ${ }^{[10]}$ 
Registration of the activity of individual vagal preganglionic and postganglionic sympathetic cardiac neurons showed that heart motor neurons initially respond to conventional signals and determine the formation and magnitude of the response caused by the conditioned signal. ${ }^{[1]}$ Thus, the conditioned reflex underlying HRVB has a specificity of formation at all levels of regulation: from the heart motor neurons to the cortical brain centers.

The method of HRVB is intended to increase the total HRV, vagal influences on HR, and the baroreflex activity. ${ }^{[12,13]}$ It is shown that the application of HRVB helps to normalizing $\mathrm{BP}$, increasing vagal reserve of autonomic regulation of cardiac activity. ${ }^{[13,14]}$ Realization of the biofeedback effect is possible with the optimal functioning of the higher nervous activity mechanisms (motivation, memory, emotional and positive reinforcement) and cortical-visceral relations from the cardiovascular centers in the brain to the cardiac conduction system.

The total power (TP) of HRV spectrum as a controlled parameter is promising for use to enhance vagal influences on the heart rhythm. During short-term recording (5 minutes), this parameter is similar to standard deviation of RR interval in the physiological meaning and reflects the increase in vagal influences on the heart rhythm. A person manages the parameters of HR primarily through a voluntary change in the frequency and depth of breathing. Consequently, the successful increase in TP of HRV spectrum using biofeedback technology in persons with a normal cardiorespiratory interaction is possible during several sessions ${ }^{[15]}$ or even within a single session. We have shown differences in the reactivity of brain structures in adolescents with sympathicotonia and normotonia after the first session of HRVB. Adolescents with sympathicotonia on the background of increased alpha EEG activity and decreased BP demonstrated the reduction in initially increased theta EEG activity, while the adolescents with normotonia had only increased alpha EEG activity. After 10 sessions of HRVB in adolescents with sympathicotonia, EEG indices and BP were comparable to those of adolescents with normotonia. ${ }^{[16]}$ Krivonogova et al. ${ }^{[17]}$ showed that people with high endurance, flexibility and tempo, and the moderate emotion demonstrated a persistent increase in TP after the first session and the next 10 sessions. Thus, these people have a high level of coordination of all sub-systems of the mental processes and body regulation. Individuals with the moderate endurance, plasticity, tempo and emotion demonstrated a significant increase in TP (in comparison with baseline values) after 4-5 sessions HRVB training. In individuals with low values for each of the mentioned properties, TP increased from session to session. ${ }^{[17]}$ These data showed that since the first session of HRVB, the adjustment function of neural networks in humans will depend on a person's initial autonomic nervous tone and psychological status.

Kappes et al. ${ }^{[18]}$ studied the possibilities of biofeedback technology for human adaptation to extreme climatic conditions. It was concluded that skillful training with bio-behavioral methods contributes to the survival and effectiveness of living in the Arctic. The cold pressor test is a demonstrative model that reflects the body's reactivity in conditions of hypothermia.
Skills acquired via HRVB during immersion of hands in cold water help to reduce a pain in the hands' skin during local hypothermia. ${ }^{[19]} \mathrm{A}$ person's ability to raise his or her own HRV in a short time, and even during a single biofeedback session, can be seen as cognitive test of adaptation to uncomfortable environmental factors. Moreover, different versions of changes in the brain's bioelectrical activity reflect the various cognitive strategies during biofeedback training. In a study by Krivonogova et al., ${ }^{[20]}$ a single session of HRVB was carried out in healthy adolescents aged between 14 and 17 years in order to increase vagal effects on heart rhythm. Five different variants of EEG spectral power during the successful HRVB session were identified. These individual cognitive strategies during biofeedback sessions reflected the activation of the thalamic-cortical system or cortical-hippocampal system, as well as local cortical brain activity. It was shown that after a single session of HRVB in adolescents living in the polar areas $\left(67^{\circ} 40^{\prime} \mathrm{N}\right)$, especially in patients with sympathicotonia, theta EEG activity decreased more intensively with a predominance of the dynamics in the right brain hemisphere compared to adolescents living in the subpolar region $\left(64^{\circ} 30^{\prime} \mathrm{N}\right)$. Moreover, the changes of EEG activity continued after the biofeedback session in adolescents living in the polar areas. ${ }^{[21]}$ After a single session of HRVB among adolescents living above the Polar Circle $\left(67^{\circ} 40^{\prime} \mathrm{N}\right)$, a more prolonged increase in alpha EEG activity was identified on the background of a more pronounced decrease in theta EEG activity and decreased reaction of assimilation of photostimulation rhythm in comparison with adolescents living below the Polar Circle $\left(64^{\circ} 30^{\prime} \mathrm{N}\right)$. Changes in EEG pattern are most characteristic for the right hemisphere with involvement of the frontal parts of the brain. ${ }^{[22]}$ In adolescents, after a single session of HRVB in order to increase the TP, different versions of changes in the time of a long-latency auditory evoked potential (P300) were found. These data reflect the options of integrating neurons to optimize the balance of the sympathetic and vagotropic mechanisms. In the first variant, there is an optimization in the level of excitation and inhibition in neural networks, which is reflected in the decrease of P300 latency in the parietal, central, frontal and temporal brain regions. In the second variant, there is an increase in the internal differential inhibition to achieve a successful biofeedback control, which is reflected in the prolongation of the initially very short $\mathrm{P} 300$ latency. ${ }^{[23]}$

Demin et al. ${ }^{[24]}$ studied the role of hormones of the pituitary-thyroid system in changing the brain bioelectric activity during a short HRVB session in adolescents aged from 15 to 17 years. In individuals with sympathicotonia, the changes of amplitude-frequency EEG characteristics were directly dependent on the serum thyrotropin levels during the HRVB session and after it. ${ }^{[24]}$ It was shown that individuals with low serum serotonin levels after a single HRVB session had higher activation of brain structures than individuals with normal levels of serotonin. ${ }^{[25]}$ Modern man must adapt to the uncomfortable factors of nature and social life. It was shown that the short-term HRVB session, increasing the total HRV, helps to reduce stress and anxiety. ${ }^{[2]}$ Moreover, shortterm HRVB training reduces anxiety more than walking. ${ }^{[27]}$ There are a specific local changes in brain activity reflecting 
an increase in internal attention combined with relaxation both during and after this procedure. ${ }^{[28]}$ Thus, analysis of the literature showed the effectiveness of short-term HRVB training with regard to the optimization of autonomic tone and improvement of the functions of central nervous system. The main mechanisms for realization of HRVB include the resonance effect of certain HRV frequencies, activation of baroreflex and neuronal connections between the vagus nerve and the brain structures, especially, the frontal lobes. ${ }^{[12,13]}$ It has been shown that a single HRVB session can significantly reduce subjective anxiety in musicians. ${ }^{[29]}$ In addition, this method has certain advantages over passive relaxation. ${ }^{[30]}$ Currently, more and more people are using computer games with biofeedback on various physiological parameters, including HR. Some authors have shown that most people are able to control their physiological functions after a single session of biofeedback. The game participants in pairs were more successful in biofeedback training than were single players. $^{[31]}$

Researchers have found that a short-term HRVB session in adults with different BP levels has prognostic significance. In people with normal BP, the TP increased significantly, the stress indexes decreased, and oxygen saturation increased. In hypertensive individuals without drug treatment, a low success of HRVB on the background of high sympathetic reactivity was detected. In hypertensive people with drug correction, vagal reactivity was more pronounced than in those without drug correction, which was reflected in a significant increase in the TP compared to the baseline values. Oxygen saturation was not changed in comparison with the baseline values in those of two previous groups. ${ }^{[32-34]}$ Thus, the ability of HRVB to increase the TP during the standard short-term recording (5 minutes) can be regarded as a test for the determination of the preserved vagal reserve in patients with high BP. However, the oxygen saturation in this case is a non-informative indicator of biofeedback effectiveness in people with hypertension. Previously, other authors on the example of skin temperature biofeedback training (single session) in persons with heart failure also showed minimal changes in oxygen saturation on the background of optimizing cardiac output and total vascular resistance. ${ }^{[35]}$

Despite the presence of a large database of evidence supporting the efficacy of HRVB training, there exist debatable questions of the sustainability of the biofeedback effect sustainability ${ }^{[36]}$ It has been shown that after a single 20-minute HRVB session, persons with psychotic disorders could increase the perceived control. However, there were no differences in HRV indices and symptoms of stress and paranoia in people who carried out the biofeedback session and in people from the control group did. ${ }^{[37]}$ Other authors have observed that psychological stress, fear and anxiety significantly decreased in difficult-to-wean patients requiring prolonged mechanical ventilation after four HVRB sessions. However, HRV indices after this intervention did not differ significantly from baseline values. ${ }^{[38]}$

In conclusion, this brief review demonstrates the effectiveness of short-term HRVB sessions in an evaluation of human adaptation to uncomfortable environments. A single
HRVB session can be used as a test for the effectiveness of cortical-visceral connections in patients with cardiovascular disease. In addition, this method can be used as short-term assistance in adaptation to social stressful factors. However, there are certain limitations in the application of this method. First, low reactivity of some levels of vascular regulation and blood gas parameters during the first HRVB session was detected in people with impaired vascular tone. Secondly, the effects of HRVB training on HRV and clinical manifestations of disease did not always coincide in time. In the above cases, the use of long-term courses of HRVB will be more advisable.

\section{Competing interests}

The authors declare that they have no competing interests.

\section{References}

1. Eller NH. Total power and high frequency components of heart rate variability and risk factors for atherosclerosis. Auton Neurosci. 2007;131(1-2):123-30. doi: 10.1016/j.autneu.2006.08.002

2. Corino VD, Matteucci M, Mainardi LT. Analysis of heart rate variability to predict patient age in a healthy population. Methods Inf Med. 2007; 46(2):191-5.

3. Goldstein DS. Neuroscience and heart - brain medicine: the year in review. Cleve Clin J Med. 2010;77 Supple 3:S34-9. doi: $10.3949 /$ ccjm.77.s3.06.

4. Thayer JF, Ahs F, Fredkikson M, Sollers JJ 3rd, Wager TD. A meta-analysis of heart rate variability and neuroimaging studies: implications for heart rate variability as a marker of stress and health. Neurosci Biobehav Rev. 2012;36(2):747-56. doi: 10.1016/j.neubiorev.2011.11.009.

5. Ahs F, Sollers JJ. 3rd, Furmark T, Fredrikson M, Thayer JF. High-frequency heart rate variability and cortico-striatal activity in men and women with social phobia. Neuroimage. 2009;47(3):815-20. doi: 10.1016/j.neuroimage.2009.05.091.

6. Lane RD, McRae K, Reiman EM, Chen K, Ahern GL, Thayer JF. Neural correlates of heart rate variability during emotion. Neuroimage. 2009; 44(1):213-22. doi: 10.1016/j. neuroimage.2008.07.056.

7. Critchley HD, Taggart P, Sutton PM, Holdright DR, Batchvarov V, Hnatkova K, et al. Mental stress and sudden cardiac death: asymmetric midbrain activity as a linking mechanism. Brain. 2005;128 (Pt 1):75-85. doi: 10.1093/brain/awh324.

8. Buchanan S, Powell D. Hyppocampal lesions and Pavlovian cardiovascular conditioning. Pavlov J Biol Sci. 1982;17:158-64.

9. Morse WH, Skinner BF. Some factors involved in the stimulus control of operant behavior. J Exp Anal Behav. 1958;1:103-7. doi: 10.1901/jeab.1958.1-103

10. Cohen DH, Randall DC. Classical conditioning of cardiovascular responses. Annu Rev Physiol. 1984; 37:18797. doi: 10.1146/annurev.ph.46.030184.001155

11. Gold MR, Cohen DH. The discharge characteristics of vagal cardiac neurons during classically conditioned heart rate change. J Neurosci. 1984:4(12):2963-71

12. Lehrer PM, Gevirtz R. Heart rate variability biofeedback: how and why does it work? Front Psychol. 2014;5:756 doi: 10.3389/fpsyg.2014.00756.

13. Lin G, Xiang Q, Fu X, Wang S, Wang S, Chen S, et al. Heart rate variability biofeedback decreases blood pressure in 
prehypertensive subjects by improving autonomic function and baroreflex. J Altern Complement Med. 2012;18(2):14352. doi: 10.1089/acm.2010.0607.

14. Nolan RP, Floras JS, Harvey PJ, Kamath MV, Picton PE, Chessex C, et al. Behavioral neurocardiac training in hypertension: a randomized, controlled trial. Hypertension. 2010;55(4):1033-9. doi: 10.1161/ HYPERTENSIONAHA.109.146233.

15. Siepmann M, Aykac V, Unterdorfer J, Petrowski K, Mueck-Weymann M. A pilot study on the effects of heart rate variability biofeedback in patients with depression and in healthy subjects. Appl Psychophysiol Biofeedback. 2008;33(4):195-201. doi: 10.1007/s10484-008-9064-z.

16. Demin D, Poskotinova L, Grjibovsky AM, Varakina Z. Neurophysiological effects of heart rate variability biofeedback training in adolescents: a Russian study. Int J Epidemiol. 2015;44(1) Suppl 1:216. doi: 10.1093/ije/dyv190. 17. Krivonogova E, Demin D, Poskotinova L, Grjibovski A. Assessment of heart rate variability biofeedback in people with the different individual psychodynamic properties. Eur J Epidemiol. 2013;28(Suppl 1):129. doi: 10.1007/s10654-013-9820-0.

18. Kappes B, Mills W, O’Malley J. Psychological and psychophysiological factors in prevention and treatment of cold injuries. Alaska Med. 1993;35(1):131-40.

19. Reeves JL 2nd, Shapiro D. Heart-rate reactivity to cold pressor stress following biofeedback training. Biofeedback Self Regul. 1983;8(1):87-99.

20. Krivonogova EV, Poskotinova LV, Demin DB. Individual Types Reactivity of EEG Oscillations in Effective Heart Rhythm Biofeedback Parameters in Adolescents and Young People in the North. Zh Vysh Nerv Deiat Im IP Pavlova. 2015; 65(2):203-11. doi: 10.7868/S0044467715020069. [Article in Russian].

21. Demin DB, Poskotinova LV, Krivonogova EV. EEG reactions during heart rate variability biofeedback procedure in adolescents with different autonomic tone living in Northern areas. Human Ecology (Russian Journal). 2016;10:23-30. [Article in Russian].

22. Demin DB, Poskotinova LV, Krivonogova EV. Comparison of electroencephalogram changes at cardiovascular training in adolescents of subpolar and polar northern territories. Ross Fiziol Zh Im I M Sechenova. 2014; 100(1):128-38. [Article in Russian].

23. Krivonogova EV. Features of auditory cognitive evoked potentials p300 in successful heart rate variability biofeedback in adolescents living in Arctic area. Human Ecology (Russian Journal). 2016;1: 26-31 [Article in Russian].

24. Demin DB, Poskotinova LV, Krivonogova EV. Thyroid effect on brain activity in adolescents during heart rhythm biofeedback session. Ross Fiziol Zh Im IM Sechenova. 2011; 97(11):1262-9. [Article in Russian].

25. Krivonogova EV, Poskotinova LV, Demin DB. Comparative analysis of the EEG components and heart rate variability during biofeedback training, depending on the serotonin serum level at girls $15-17$ years. Byulleten Sibirskoy Meditsiny. 2011; 10(4): 21-26. [Article in Russian].
26. Prinsloo GE, Derman WE, Lambert MI, Rauch HG Laurie. The effect of a single episode of short duration heart rate variability biofeedback on measures of anxiety and relaxation states. Int J Stress Manag. 2013;20(4):391-411. doi: 10.1037/a0034777.

27. Meier NF, Welch AS. Walking versus biofeedback: a comparison of acute interventions for stressed students. Anxiety Stress Coping. 2016;29(5):463-78. doi: 10.1080/10615806.2015.1085514.

28. Prinsloo GE, Rauch HG, Karpul D, Derman WE. The effect of a single session of short duration heart rate variability biofeedback on EEG: a pilot study. Appl Psychophysiol Biofeedback. 2013; 38(1):45-56. doi: 10.1007/s10484-012-9207-0.

29. Wells R, Outhred T, Heathers JA, Quintana DS, Kemp AH. Matter over mind: a randomised - controlled trial of single session biofeedback training on performance anxiety and heart rate variability in musicians. PLoS One. 2012;7(10):e46597. doi: 10.1371/journal.pone.0046597.

30. Sherlin L, Gevirtz R, Wyskoff S, Muench F. Effects of respiratory sinus arrhythmia biofeedback versus passive biofeedback control. Int J Stress Manag. 2009;16(3):233-48. doi: $10.1037 / \mathrm{a} 0016047$.

31. Parente A, Parente R. Mind-operated devices: Mental control of a computer using biofeedback. Cyberpsychol Behav. 2006; 9(1):1-4. doi: 10.1089/cpb.2006.9.1.

32. Poskotinova L, Demin D, Krivonogova E, Grjibovski A. Detection of a decrease in vagal regulation of cardiac activity in patients with hypertension. Eur J Epidemiol. 2013;28(Suppl 1):91. doi: 10.1007/s10654-013-9820-0

33. Poskotinova LV, Demin DB, Krivonogova EV, Dieva MN, Khasanova NM. The success of heart rate variability biofeedback parameters in persons with different levels of blood pressure. Vestnik Ross Akad Med Nauk. 2013;7:20-23. [Article in Russian]

34. Poskotinova LV, Semenov YuN. Method for correcting vegetative misbalance states with Varicard complex for processing cardiointervalograms and analyzing cardiac rhythm variability, operating under computer software program with biofeedback. Patent RU 2317771. Application: 2006110652/14, 03.04.2006. Date of publication 27.02.2008. [in Russian]

35. Moser DK, Dracup K, Woo MA, Stevenson LW. Voluntary control of vascular tone by using skin-temperature biofeedback-relaxation in patients with advanced heart failure. Altern Ther Health Med. 1997; 3:51-59.

36. Wheat AL, Larkin KT. Biofeedback of heart rate variability and related physiology: a critical review. Appl Psychophysiol Biofeedback. 2010;35(3):229-42. doi: 10.1007/s10484-0109133-y.

37. Clamor A, Koenig J, Thayer JE, Lincoln TM. A randomized-controlled trial of heart rate variability biofeedback for psychotic symptoms. Behav Res Ther. 2016; 87: 207-15. doi: 10.1016/j.brat.2016.10.003.

38. Chen Yu-Ju, Hwang Shiow-Li, Lee Chu-Yi. The feasibility of biofeedback in difficult-to-wean mechanically ventilated patients: Apilot study. Eur Respir J. 2013; 42(57):4225 